\title{
Opening a M. Sc. in Electrical Engineering for Non-Traditional Students
}

\author{
Preparation of Applicants Without Prior Academic Education for a Master's Course \\ http://dx.doi.org/10.3991/ijac.v5i2.2119
}

\author{
A. L. Müller ${ }^{1}$, A. Schwarzbacher ${ }^{1}$ and B. Hoppe ${ }^{2}$ \\ ${ }^{1}$ Dublin Institute of Technology, Dublin, Ireland \\ ${ }^{2}$ University of Applied Sciences Darmstadt, Darmstadt Germany
}

\begin{abstract}
This paper will discuss why and how the University of Applied Sciences, Darmstadt/Germany will identify core competences of bachelor's degrees in Electronic Engineering and develop specially tailored life-long learning programmes for non-traditional students. These programmes will enable highly qualified master craftsmen, solely educated to the level of master craftsmen, to successfully participate in the existing Master of Science in Electronic Engineering programme. Furthermore, this paper will present the initial results obtained from a pilot project group.
\end{abstract}

Index Terms_-Lifelong Learning, Engineering Education, Recognition of prior learning (RPL), Continuous professional development (CPD), Non-traditional students, Qualified master craftsmen to master

\section{INTRODUCTION}

According to the latest Hessian (a state in Germany) University State Law §16 HHG [1], highly qualified master craftsmen have the right to apply for nonconsecutive Master's programmes without any prior university education. To enter a master programme knowledge equivalent to that of an honours bachelor level degree has to be demonstrated by passing an entrance exam. This results in a major challenge for universities in Hesse, as no experience exists whether master craftsmen can be successful at a master level. Therefore, it is crucial to develop a robust selection process to choose qualified applicants. Also, knowledge levels of applicants are expected to be strongly incoherent. Moreover, the fundamental question of what are the differences between the skills gained in a

Bachelor's programme and the experience gained through successful practical work on industrial projects over a number of years has to be answered. The main difference of these students when compared to entrance holding a bachelor degree is expected to be in scientific methodology, especially in sciences and in mathematical methods needed for electrical engineering. These fields have to be tested and it is very unlikely that a master craftsman will pass such a test without dedicated prior training in a preparatory programme.

Germany has a severe lack of skilled workers in all fields of engineering and sciences. At the moment Germany's industry has approximately 80.000 jobs vacant in these fields [2]. Therefore, the political framework for university access was changed by the government, to provide a transparent and flexible avenue towards a university degree for everybody, who has the appropriate ability, motivation and experience [3]. Typically, experienced and senior staff from industry will not want to carry out a Bachelor's degree. Therefore, politics has created a route for highly skilled workers to enter universities directly at Master's level. Neither the University of Applied Sciences Darmstadt (H_DA) nor any other Universities of Applied Sciences in Hesse do have experience with highly qualified master craftsmen participating in a Master of Science programme in Electrical Engineering. In June 2011, a pilot group of eight students was admitted for the Electrical Engineering (M.Sc.) programme at H_DA. This group participates in a preparatory program, which started in June 2011 to be prepared specifically for the Master programme. The programme is a distant learning course. One challenge that needs to be taken into account is the fact that Electric Engineering is a programme located in the field of STEM (Science, Technology, Engineering and Mathematics). Therefore, laboratory experiments play an important role, which requires a certain minimum amount of attendance at the H_DA. Furthermore, it is important to optimise the distance learning material especially for these non-traditional students. As literature shows, today many adults like to use online environments, because they have busy schedules and the online format is very convenient to them [4]. Not only will the non-traditional students have to receive optimum distance learning materials, also the preparatory program plays a key role in the later success in their studies. In this paper, the structure of this preparatory programme as well as first results will be described.

\section{Preparatory Course: An OVERVIEW}

The preparatory programme will be offered over two semesters as a part-time programme. After completing the modules, the students will be ready to take the Master of Science entrance exam. After that, learners will be advised whether to take part in a Bachelor's programme first or directly start with a Master's programme. If students start with a Bachelor's programme, it is possible to give credits for some of the classes already taken and to take additional prior learning into account to provide an appropriate entry point. Due to the broad practical experience, technical and practical deficits in specialties of the field are not expected. The main difference of the qualification of these non-traditional applicants as compared to students holding a Bachelor's degree is the lack in abstraction capability and theoretical foundation in describing and dealing with 
technical systems. Based on this assumption, the topics of the modules in the pre-studies programme are mathematical methods and system theory; nevertheless, these modules will have to be tested and their usefulness has to be verified by monitoring the students' success during the Master's programme. Therefore, the programme to be implemented is currently being tested and further optimised, as described in Chapter III: Approach. The learning material is distributed in printed versions; five scripts (100 pages each) were mailed to the students defining and explaining the topics mentioned above. After the prestudies course, students of the pilot group will continue with the Master's programme.

\section{APPROACH}

The novelty about this project is the fact that nontraditional students will participate in a Master's programme, not in a Bachelor's programme. The goal therefore is to prepare these students with a focus on the Master's programme on electrical engineering. Also the training of non-traditional students with a preparatory course is a standard approach. However, in this case the contents of the preparatory course were tailored specifically taking into account the requirements of the Master program's modules. To find knowledge gaps, interviews with experts in the field of teaching and assessing non-traditional students were held, and the conclusions were assigned to three different study fields. Basically the three relevant fields where non-traditional students are expected to lack knowledge are:

1. Self-management, Learning organisation and information retrieval

2. Engineering methodology, abstraction and formalisation of scientific/technical issues

\section{Documentation and dissemination}

Instead of questionnaires checking practical experience as well as recent exposure to the above issues, it was decided to use a course on mathematical methods for electrical engineers as an avenue to achieve the multidimensional goals, so to say in a nutshell. The students were given three learning units about mathematics on high school level, without other information and they were asked to go through the material and to complete the problems given in the texts. Immediately the students formed learning groups, indentified complex subjects by themselves and retrieved additional information from open sources in the internet or from libraries. Some students joined evening courses offered by the "Volkshochschule" (non-profit making entity that offers adult education in a broad spectrum of fields). The students prepared lists of questions and mailed them to our electrical engineering institute and insisted on qualified answers, which we willingly provided. Monitoring these efforts by online support and three dedicated seminars during the relevant time period convinced that this issue No. 1 (see list above) was well managed by the students and other tests or trainings are not required. In two other learning units the students were confronted with system theoretical methods in electrical engineering to train their abstraction capabilities and theoretical competences. In system theory integral transformations are of special importance: Theory of Functions, Fourier-transformation, Laplace-transformation, Z-transformation and the classification of systems using these mathematical abstractions. Here the students were trained in advanced engineering methodology, which is not a topic in practical work and clearly the gap, which has to be closed to work on an engineering level. These efforts are ongoing and two more weekend seminars will have to take place with the students to discuss open questions and to perform exercises and case studies. The main difference between work floor and an engineering centre is that an engineer generates information and a worker receives information about technical processes (issue No. 3). To test the dissemination capabilities the students will be asked to hold a seminar presentation about a technical problem which requires specific methods addressed in the course material on mathematical methods.

Whether these pre-studies qualify the students with their fully practical background to succeed in the Master's course will be evaluated by means of their success in the following Master's programme. Also, their personal opinion about their readiness for a Master's programme will be questioned using questionnaires before the Master's modules begin. The correlation between their selfassessment and the performance later on will be very interesting. Currently E-Learning methods for this precourse which can either be synchronous (real-time) or asynchronous (flex-time) are developed. Synchronous communication includes chat rooms and audio/video conferencing [5], and of this media will also be taken use. Therefore, a virtual classroom will be used especially for the pilot group, with tutors answering questions on a regular base.

\section{COMPOSITION OF THE PilOt GROUP}

The participants' age ranges from 28-51 years. All participants are male, and currently are full-time employed in the field of electrical engineering.

The participants' total practical experience ranges from 7-31 years. This includes all practical experience gained after the highest school diploma. The average practical experience is 20.1 years. This shows that all of the participants have gained significant practical experience. According to Hessian State Law [1], a minimum of various years of practical experience is required, with no explicit number of years stated. In order to qualify for the pilot project at the H_DA, a minimum of three years of qualified practical experience were required.

The group consists of three state certified technicians and five master craftsmen. A person holding either of those degrees will be, according to Hessian State Law [1], allowed to participate in the master programme. Nevertheless, differences exist in the learning content and duration of the education. Therefore, performance will be measured also with a focus on the different groups, in order to find out, how each performs in various fields of study in the Master's programme.

In order to assess the communication skills beforehand, there were personal interviews with all the candidates for the Master course with a non standard background. These individual interviews lasted one hour and covered the job situation as well as private aspects, since balancing work, life and education on a master's level is a demanding task. The candidates also provided a detailed letter of motivation and a CV. Further applicants will be asked to hand in a detailed report about a recent industrial project in order to be able to assess the applicants' writing capability more closely. 


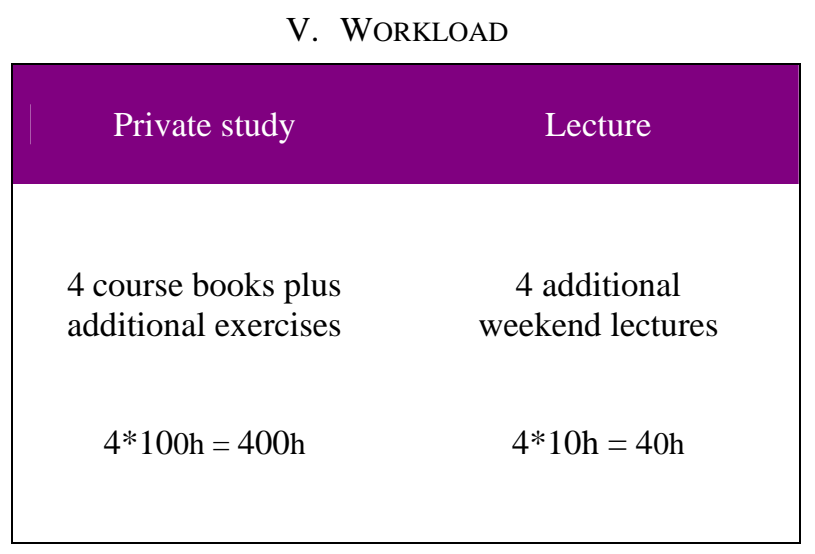

Figure 1. Amount of work spent in the preparatory course (in hours)

Since the pre-course has to be manageable with a full time job, workload is critical. So the students were asked to provide a study diary. So far, four course books plus additional exercises have been covered, which sums up to 440 hours of private studies spent. Since the participants of the pilot group have never gotten in touch with academic learning material, the time needed for each course book is more then the learning estimated for academically trained personal for the same amount of course content. Due to our findings the time factor is between 1.5 and 2, which leads to 100 hours private study for one course book. Furthermore, four additional weekend lectures have been held, amounting to another 40 hours. Currently (state of November 2011), 440 hours in total, have been spent in preparatory training by the students of the pilot group.

\section{PRE-COURSE STRUCTURE}

After the findings from working with the pilot group, the preparatory program will be offered for the next batch of students over two semesters as a part-time programme, which represents one year of preparation to relax the tough time schedule, which was one major issue for the pilot group. After completing the modules, the students will be ready to take a structured M.Sc. entrance exam. For the pilot group the examination was a detailed interview with professors teaching on the Master's programme.
After the entrance exam, learners will be advised whether to take part in a Bachelor's programme first or to directly start with a Master's programme. If students start with a Bachelor's programme, it is possible to give credits for some of the classes already taken in the preparatory course and to take into account additional prior learning to provide an adequate entry possibility. Besides gaining theoretical knowledge, future students also learn scientific research methods and project documentation. The following list shows the topics of the modules that the students will have to take in the preparatory programme.

\section{P1: General knowledge STEM}

In P1 general knowledge for STEM (Science, Technology, Engineering and Mathematics) disciplines is taught.

- Mathematics part I (algebra)

- Mathematics part II (functions)

- $\quad$ Mathematics part III (geometry)

P2: Special knowledge

In P2 special knowledge for the Electrical Engineering programme at the H_DA is taught.

- Mathematical methods for electrical engineers part I

- $\quad$ Mathematical knowledge for electrical engineers part II

- $\quad$ Programming: java (start in 2012)

P3: General knowledge for university studies P3 includes general knowledge for university studies. Students are taught how to use for example the online platform moodle, or encouraged to form study groups.

- Virtual classroom: E-Learning

- $\quad$ Study groups

- Methods of scientific research and work. Also study techniques will be taught (start: 2012)

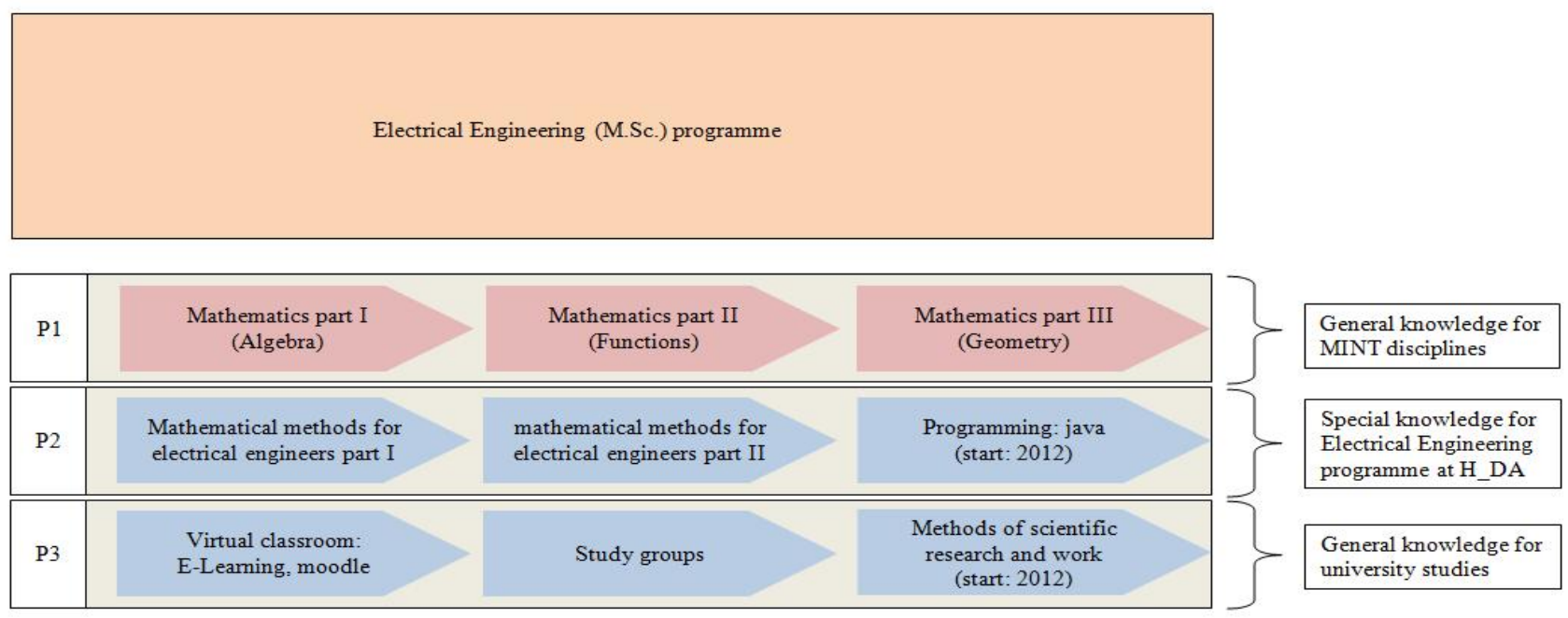

Figure 2. Overview of additional Modules for non-traditional Student Group 


\section{THE MASTER's PROGRAMME}

To illustrate, what the pre-course should qualify for, we will describe briefly the structure of the master's programme. The Master's programme consists of 120 ECTS points. The duration is six semesters part-time, in a distance learning mode. This corresponds to four semesters of full time study.

The programme is offered at the H_DA in cooperation with the University of Applied Sciences Aschaffenburg [6] and the ZFH (Zentralstelle für Fernstudien an Fachhochschulen/Centre for Distance Teaching and Learning at Universities of Applied Sciences [7]). The ZFH currently offers 20 distance learning programmes to about 2600 students at 18 cooperating Universities of Applied Sciences in Hesse, Rhineland Palatina and Saar.

The Master's course in Electrical Engineering exists for almost four years, and therefore, significant experience has already been gained in offering distance-learning modules. The programme "Qualified Master Craftsmen to Master" will therefore be run in close cooperation with the ZFH as well. The Master's course qualifies students in the fields of microelectronics, automation and power electronics as well as economics and other non-technical skills required in a professional environment. Currently there are 88 students enrolled in the existing programme and about 30 students have so far graduated from the MSc.

The students receive learning materials to study at home. However, to reduce the high dropout rate of similar long distance programmes learning will not be limited to learning by themselves. Students have the opportunity to find further teaching material at the online platform "Moodle". This is a well-accepted opportunity to interact with each other for example in bulletin boards and answer each others' questions. Additionally, weekend learning sessions take place. This means that the students must come to the H_DA or its partner, the University of Applied Sciences Aschaffenburg and take part in face to face lectures and laboratories every four to six weeks. This will help to advance the learning process and it is also part of team building. The participants get to know one another, they can interact with each other, share their knowledge and it is less likely that students feel isolated. This reduces the drop-out rate [8].

The didactical and organisational framework for the “Qualified Master Craftsmen to Master"-students therefore is already given. After a successful entrance programme the master craftsmen will participate in the Electrical Engineering programme together with engineers holding a bachelor's degree in Electrical Engineering or related fields to enhance interaction between learning groups with different educational background.

The following list shows the modules (the modules BE1 and BE2 have been added in 2010 by the H_DA [9]; list of the modules according to [10]).

A1: Verbal Communication

A2: System-Design and Objects

A3: Signals, Systems, Simulation

BA1: Control Theory

BA2: Automation

BE1: Power Engineering (Energy production)

BE2: Power Engineering (Energy distribution)
BM1: Microelectronic Design methodology

BM2: Microelectronic Technology

B3: Optional subjects (choose 4 out of 13)

C1: System development by Software- and Hardware-

Engineering

C2: Team-Project and Project Management

C3: Economics

D: Master-project, thesis and viva-voce: thesis topic from industry or university

After successfully completing the programme, both the students already holding a Bachelor's degree and the master craftsmen, will be awarded the internationally accredited award of 'Master of Science'. For qualified master craftsmen the complete programme takes four years in part time study mode. For students with a Bachelor's degree the course duration is three years.

One open question is whether or not master craftsmen are allowed to take any of the modules on offer or whether there are certain restrictions imposed or at least that they are guided in a certain field of specialisation. Usually, technical staff from industry has enough experience in the field of automation but have not been in touch with microelectronic design or vice a versa. This issue also has to be investigated during course of this project. Figure 3 gives an overview of the complete project, including the preparatory training and the Master's course.

\begin{tabular}{|c|c|}
\hline $\begin{array}{c}\text { Preparatory pro- } \\
\text { gramme }\end{array}$ & \multirow{2}{*}{ Specially tailored courses } \\
\cline { 1 - 1 } P1, P2, P3 & \\
\hline
\end{tabular}

\begin{tabular}{|c|c|}
\hline Master's Programme & \multirow{2}{}{} \\
\cline { 1 - 1 } A1-A3 & \\
BA1, BA2 & Master's programme is \\
BE1, BE2 & already existing; slight modi- \\
BM1, BM2 & fications for qualified master \\
B3 & craftsmen are possible \\
C1-C3 & \\
D & \\
\hline
\end{tabular}

Figure 3. Overview of the complete Programme

\section{RESULTS AND CONCLUSIONS}

First results are encouraging and support the validity of the approach chosen to train non-traditional applicants. It was and will be evaluated during the pre-course whether the teaching methods as well as the learning material satisfies the needs of the students in this phase of study. As the project progresses, students will be closely monitored and their success in the Master's programme will be the primary criterion to test the effectiveness of our preparatory training.

\section{A. Learning Behaviour}

As the evaluation of questionnaires shows, members of the eight person pilot group tend to be highly selforganised and show a high level of discipline. Knowledge gaps were filled by the students individually in a self directed manner. Within few days two study groups were formed by $50 \%$ of the students who regularly met each 


\section{SHORT PAPER}

\section{OPENING A M. SC. IN ELECTRICAL ENGINEERING FOR NON-TRADITIONAL STUDENTS}

other to learn together. $37.5 \%$ of the students would have liked to do so but were not able to because of a lack of time, distance to the other students as well as other reasons. Only one student decided not to join a study group.

\section{B. Academic results}

At the end of the preparatory programme a test in mathematical methods including various fields of mathematical methods such as equation solving, differential calculus, integral calculus and vector analysis was written. All of the students passed the examination (according to H_DA examination regulations, which require a minimum of $40 \%$ of points achieved). Results show that all of the test-takers answered at least $40 \%$ of all questions correctly; the highest score was at $85 \%$. No correlation was observed between test grade and qualification (state certified technician or master craftsman). It should also be noted at as of yest (November 2011), the dropout rate is zero.

\section{Survey results}

To evaluate the preparatory programme and help determine success factors, the students have been questioned in a survey. Results show that the preparatory programme so far was perceived as very helpful and satisfactory (ranked with an average grade of 9.1 out of 10 . Attendance rate for lectures (40 hours in total) was $100 \%$. This shows a well above-average motivation of the students.

The challenge for the H_DA is to choose the right nontraditional students for the electrical engineering Master's programme adequately and to prepare these students to be able to succeed in the programme. Therefore, a preparatory programme will have to be developed based on the knowledge gained from the current pilot group of students admitted for the fall semester of 2011/12. The novelty is that the students will be admitted directly into a Master's programme for electrical engineering without completing a Bachelor's degree beforehand.

The approach in this case is to tailor the contents of the preparatory course specifically taking into account the requirements of the Master programme's modules. Hereby, different educational methods are taken into account and the approach is evaluated and constantly improved.

First results of the group have been encouraging and it was shown that all of the students passed the first mathematics test which is part of general knowledge for STEM disciplines. Also, first performance results of the students in the first master's semester will be available. Based on this outcome the content of the pre-studies course will be adjusted.

\section{REFERENCES}

[1] Hessisches Hochschulgesetz $\S 16$ HHG/Hessian University State Law, legislation of December 14, 2009

[2] The Association of German Engineers. (2011). Der Arbeitsmarkt für Ingenieure im Februar [Online]. Available: http://www.vdi.de/fileadmin/vdi de/redakteur dateien/dps dateie $\underline{\text { n/SK/Ingenieurmonitor/2011/Ingenieurmonitor\%202011-03.pdf }}$

[3] Kultusministerkonferenz (2009): Hochschulzugang fürberuflich qualifizierte Bewerber ohne schulische Hochschulzugangsberechtigung [Online] Available: http://www.kmk.org

[4] Cercone, K. (2008): Characteristics of adult learners withimplications for online learning design, AACE Journal, 16(2), 137-159.

[5] Romiszowski, A. J. (2004): How's the E-learning Baby? Factors leading to Success or Failure of an Educational Technology Innovation, Educational Technology, Vol. 44, No. 1, pp.5-27

[6] Hochschule Aschaffenburg/University of Applied Sciences [Online]. Available: http://www.fh-ab.de

[7] Zentralstelle für Fernstudien an Fachhochschulen/Centre for Distance Teaching and Learning at Universities of AppliedScience [Online]. Available: http://www.zfh.de

[8] K. Solberg Søilen (2007): Increased Interactivity to Reduce DropOut Rate on Distance Learning Programs [Online] Available: http://www.bth.se/fou/forskinfo.nsf/all/2dd7509484a76fd2c12572 720046d5f7/\$file/EDEN\%20conference\%20soilen.pdf

[9] Hochschule Darmstadt/University of Applied Sciences [Online]. Available: http://www.h-da.de

[10] Masterfernstudiengang Elektrotechnik/Master of Science Programme in Electrical Engineering [Online]. Available: http://www.masterfernstudium-elektrotechnik.de

\section{AUTHORS}

A. L. Müller is with School of Electronic and Communi-cations Engineering Dublin Institute of Technology, Dublin, Ireland.

A. Schwarzbacher is with School of Electronic and Communications Engineering Dublin Institute of Technology, Dublin, Ireland.

B. Hoppe is with the Department of Electrical Engineering and Information Technology University of Applied Sciences Darmstadt, Darmstadt Germany.

Received 17 May 2012. Published as resubmitted by the authors 27 May 2012. 